\title{
PENGARUH KEEFEKTIFAN PENGENDALIAN INTERNAL, ASIMETRI INFORMASI, KESESUAIAN KOMPENSASI DAN KETAATAN ATURAN AKUNTANSI TERHADAP KECENDERUNGAN KECURANGAN AKUNTANSI (Studi Kasus pada OPD Kabupaten Kendal)
}

\author{
Lilik Nur Indah ${ }^{1}$, Sobrotul Imtikhanah ${ }^{2}$, Tutut Dwi Andayani ${ }^{3}$, Felinda \\ Ainur Rachmani ${ }^{4}$ \\ ${ }^{123}$ Program Studi S1 Akuntansi, Fakultas Ekonomika dan Bisnis Universitas \\ Muhammadiyah Pekajangan Pekalongan \\ 4 Program Studi D3 Akuntansi Fakultas Ekonomika dan Bisnis Universitas \\ Muhammadiyah Pekajangan Pekalongan \\ Email : dwiandayani583@gmail.com
}

\begin{abstract}
Abstrak
Penelitian ini bertujuan untuk menguji pengaruh keefektifan pengendalian internal, asimetri informasi, kesesuaian kompensasi dan ketaatan aturan akuntansi terhadap kecenderungan kecurangan akuntansi. Penelitian ini termasuk dalam metode kuantitatif dengan menggunakan data primer yang diperoleh secara langsung dari jawaban responden atas kuesioner. Populasi dalam penelitian ini adalah semua pihak yang berwenang dan bertanggungjawab dalam penggunaan dana yang dianggarkan, pelaksana akuntansi dan orang-orang yang tugasnya berkaitan dengan penyusunan laporan keuangan dan laporan pertanggungjawaban di OPD Kabupaten Kendal. Penelitian ini menggunakan teknik pengambilan sampel dengan metode purposive sampling. Sampel yang digunakan dalam penelitian ini sebanyak 66 responden. Metode analisis data yang digunakan dalam penelitian ini adalah analisis regresi linear berganda menggunakan IBM SPSS Statistics 21. Hasil penelitian ini menunjukkan bahwa: (1) Keefektifan pengendalian internal berpengaruh signifikan terhadap kecenderungan kecurangan akuntansi, (2) Asimetri informasi berpengaruh signifikan terhadap kecenderungan kecurangan akuntansi, (3) Kesesuaian kompensasi tidak berpengaruh signifikan terhadap kecenderungan kecurangan akuntansi, (4) Ketaatan aturan akuntansi tidak berpengaruh signifikan terhadap kecenderungan kecurangan akuntansi, (5) Keefektifan pengendalian internal, asimetri informasi, kesesuaian kompensasi dan ketaatan aturan akuntansi secara simultan berpengaruh signifikan terhadap kecenderungan kecurangan akuntansi.
\end{abstract}

Kata kunci : keefektifan pengendalian internal, asimetri informasi, kesesuaian kompensasi, ketaatan aturan akuntansi dan kecenderungan kecurangan akuntansi. 


\title{
THE EFFECT OF INTERNAL CONTROL EFFECTIVENESS, INFORMATION ASYMMETRY, SUITABILITY COMPENSATION AND COMPLIANCE OF ACCOUNTING RULES TO TENDENCY TO ACCOUNTING FRAUD (Case Study on OPD of Kendal Regency)
}

\begin{abstract}
This study aims to test the effectiveness of internal control, information asymmetry, suitability of compensation and compliance of accounting rules against tendencies of accounting fraud. This study used quantitative methods with primary data obtained directly from respondents's answer to questionnaries. The population in this study is all the authorities and responsible for the use of budgeted fubds, accounting implementes and people whose duties are related to the preparation of financial statements and accountability reports ini OPD Kendal Regency. This study used purposive sampling method with 66 respondents as the sample. The data analysis method used in this study was multiple linear regression analysis with IBM SPSS Statistics 21. The results of this research showed that (1) The effectiveness of internal control has a significant effect on the tendency of accounting fraud, (2) Information asymmetry has a significant effect on the tendency of accounting fraud, (3) The suitability of compensation has no significant effect on the tendency of accounting fraud, (4) Compliance of accounting rules has no significant effect on the tendency of accounting fraud, (5) Effectiveness of internal control, information asymmetry, the suitability of compensation and the observance of accounting rules simultaneously have a significant effect on the tendency of accounting fraud.
\end{abstract}

Keywords: internal control effectiveness, information asymmetry, suitability of compensation, compliance of accounting rules and tendency to accounting fraud.

\section{PENDAHULUAN}

Fraud bisa terjadi di sektor swasta maupun sektor pemerintahan. Pada sektor swasta fraud terjadi pada pengelolaan sumber dana yang tidak tepat, sedangkan dalam pemerintahan, kebocoran APBN merupakan salah satu bentuk fraud (Thoyibatun, 2009). Menurut Firdaus (2018), pada sektor pemerintahan terdapat struktur organisasi yang lebih kompleks, ketidakefektifan birokrasi, rendahnya integritas dalam lingkungan pekerjaan, ketidakefektifan pengawasan, dan tekanan yang tinggi sehingga fraud lebih banyak terjadi pada instansi pemerintah.

Berdasarkan data dari tren penindakan kasus korupsi tahun 2019 yang dilakukan oleh Indonesia Corruption Watch (ICW), disebutkan bahwa penegak hukum telah menindak sebanyak 271 kasus korupsi dengan 580 orang yang ditetapkan sebagai tersangka. Lembaga yang paling dominan terjadinya kasus korupsi adalah Pemerintah Kabupaten, Pemerintah Desa dan Pemerintah Kota. Adapun Pelaku korupsi tersebut didominasi oleh 
Aparatur Sipil Negara (ASN), swasta dan kepala desa. Adapun data lain berdasarkan survei oleh Transparency International Indonesia (TII), pejabat pemerintah daerah menempati posisi kedua sebagai lembaga atau institusi terkorup di Indonesia dengan persentase sebesar 48\% pada tahun 2020 (cnnindonesia.com, 2020).

Berdasarkan hasil survei tersebut dapat diketahui bahwa tingkat korupsi yang dilakukan oleh pejabat pemerintah daerah tergolong tinggi dibandingkan dengan lembaga atau institusi yang lain pada pemerintahan di Indonesia. Dengan banyaknya kasus korupsi yang terjadi di sektor pemerintah daerah juga menunjukkan bahwa pengelolaan keuangan daerah belum dilaksanakan dengan baik.

Pengelolaan keuangan pemerintah daerah yang baik dapat diketahui dengan pemerintah daerah yang opini Wajar Tanpa Pengecualian (WTP) yang dikeluarkan oleh BPK atas pemeriksaan Laporan Keuangan Pemerintah Daerah (LKPD). Namun, meskipun LKPD telah mendapatkan opini WTP dari BPK hal tersebut tidak menutup kemungkinan terjadinya kecurangan akuntansi di sektor pemerintah daerah karena opini WTP diberikan hanya untuk menunjukkan kewajaran informasi yang terdapat pada LKPD, bukan secara spesifik untuk menyatakan bahwa instansi yang memperoleh opini WTP tersebut telah bebas dari kecurangan akuntansi.

Penelitian ini mengacu pada penelitian yang dilakukan oleh Rifandra Adwitya dan Vita Fitria Sari (2020) yang berjudul "Pengaruh Asimetri Informasi dan Ketaatan Aturan Akuntansi Terhadap Kecenderungan Kecurangan Akuntansi di Pemerintahan Kota Payakumbuh". Persamaan penelitiannya adalah penggunaan variabel Asimetri Informasi dan Ketaatan Aturan Akuntansi terhadap Kecenderungan Kecurangan Akuntansi. Perbedaannya terletak pada penambahan dua variabel independen yaitu Keefektifan Pengendalian Internal dan Kesesuaian Kompensasi. Perbedaan lainnya yaitu peneliti memilih Organisasi Perangkat Daerah (OPD) Kabupaten Kendal sebagai objek penelitiannya.

Tujuan penelitian yang ingin dicapai oleh penelti berdasarkan permasalahan yang telah diuraikan di atas maka tujuan penelitian adalah untuk mengetahui pengaruh keefektifan pengendalian internal, asimetri informasi, kesesuaian kompensasi, dan ketaatan aturan akuntansi secara parsial terhadap kecenderungan kecurangan akuntansi pada OPD Kabupaten Kendal dan untuk mengetahui pengaruh keefektifan pengendalian internal, asimetri informasi, kesuaian kompensasi, dan ketaatan aturan akuntansi secara simultan terhadap kecenderungann kecurangan akuntansi pada OPD Kabupaten Kendal.

\section{LANDASAN TEORI DAN PENGEMBANGAN HIPOTESIS}

\subsection{Theory of Planned Behavior}

Penelitian ini didasarkan pada The theory of Planned Behavior (TPB) yang menjelaskan alasan-alasan dibalik individu dalam bertindak (Ajzen, 1991). Theory of Planned Behavior merupakan kerangka berpikir 
konseptual yang umumnya digunakan untuk menjelaskan tentang determinan perilaku tertentu. Dimana teori ini menjelaskan perilaku yang dapat mengidentifikasikan keyakinan yang dimiliki seseorang terhadap kendali atas sesuatu yang akan terjadi sebagai akibat dari perilaku yang telah dilakukan, hal tersebut dapat membedakan antara perilaku seseorang yang berniat dengan yang tidak berniat (Ajzen, 1991). Perilaku dalam penelitian ini lebih berhubungan dengan perceived behavioral control (PBC). PBC merupakan keyakinan mengenai adanya faktor pendukung ataupun faktor penghambat perilaku kecenderungan kecurangan akuntansi.

\subsection{Kecenderungan Kecurangan Akuntansi}

IAI (2001) menyatakan fraud atau kecurangan akuntansi merupakan: “(1) Kesalahan penyajian yang berasal dari kecurangan dalam pelaporan keuangan yaitu kesalahan penyajian atau penghapusan secara sengaja jumlah atau pengungkapan dalam laporan keuangan untuk menipu ataupun mengelabuhi pemakai pemakai laporan keuangan. (2) Kesalahan penyajian yang timbul dari perlakuan tidak semestinya (penyalahgunaan atau penggelapan) terhadap aset yang berkaitan dengan hilangnya aset sehingga mengakibatkan laporan keuangan tidak dapat disajikan sesuai dengan prinsip akuntansi yang berlaku di Indonesia".

\subsection{Keefektifan Pengendalian Internal}

Menurut Mardiasmo (2017), keefektifan merupakan suatu tolak ukur berhasil atau tidaknya pencapaian tujuan suatu instansi dalam rangka mencapai tujuan organisasi. Sedangkan pengendalian internaI adaIah sebuah proses yang dilakukan oleh instansi dalam rangka guna mendapatkan keyakinan bahwa instansi dapat mencapai tujuannya (Wilopo, 2006).

\subsection{Asimetri Informasi}

Menurut Wilopo (2006), asimetri informasi merupakan kondisi dimana terdapat ketidakselarasan perolehan informasi antara pihak penyedia informasi dengan pihak yang mmbutuhkan atau pengguna informasi.

\subsection{Kesesuaian Kompensasi}

Menurut Hasibuan (2017), kompensasi merupakan semua hadiah yang berbentuk barang maupun uang yang secara Iangsung dan tidak Iangsung diberikam kepada pegawai sebagai imbalan atas jasa yang telah diberikan kepada instansi. Dalam haI ini, Kesesuaian kompensasi adalah kondisi dimana pegawai merasa imbalan yang diberikan oleh instansi sesuai dengan pekerjaan yang telah dilakukan untuk instansi.

\subsection{Ketaatan Aturan Akuntansi}

Menurut Shintadevi (2015), ketaatan merupakan sikap patuh kepada perintah atau aturan yang berlaku, sedangkan aturan merupakan sebuah tindakan berdasarkan periintah yang harus ditaati. 
Dalam hal ini, ketaatan aturan akuntansi berarti suatu sikap patuh kepada aturan akuntansi yang telah ditetapkan dan yang harus dijalankan atau dituruti.

\subsection{Hipotesis Penelitian}

Gambar 1. Hipotesis Penelitian

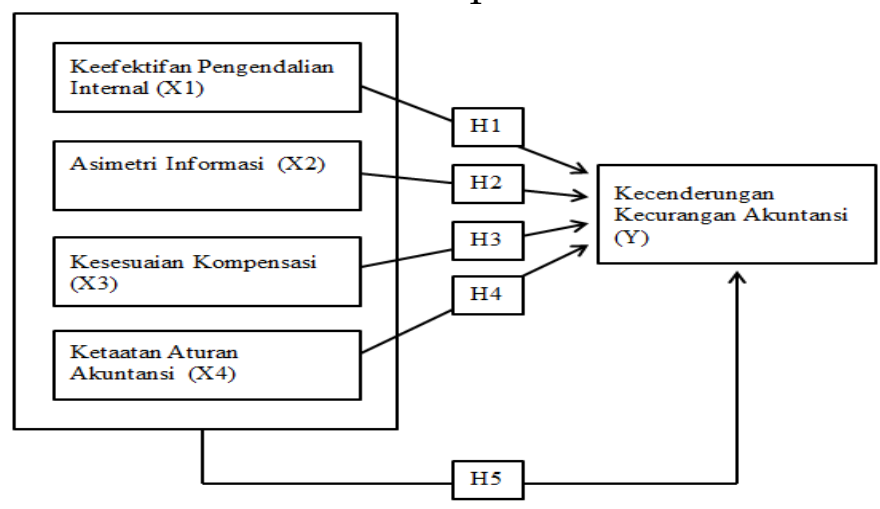

\section{METODE PENELITIAN}

3.1. Jenis Penelitian

Penelitian ini menggunakan pendekatan kuantitatif dengan mengunakan bantuan software IBM SPSS statistics 21 .

3.2. Populasi dan Sampel

Populasi dalam penelitian ini adalah pegawai yang berwenang dan bertanggungjawab dalam penggunaan dana anggaran, pelaksana akuntansi dan pegawai yang tugasnya berkaitan dengan penyusunan Iaporan keuangan serta Iaporan pertanggungjawaban di OPD Kabupaten Kendal. Penelitian ini menggunakan teknik purposive sampling dengan kriteria yang digunakan sebagai pertimbangan pemilihan sampeI dalam penelitian ini adaIah sebagai berikut:

3.2.1. Pegawai yang bekerja pada OPD Kabupaten Kendal;

3.2.2. Pegawai bagian akuntansi dan/atau keuangan (kasubbag keuangan, bendahara dan staf sub bagian keuangan); serta

3.2.3. Memiliki pengalaman kerja lebih dari 1 (satu) tahun pada OPD yang sudah ditentukan.

3.3. Sumber Data dan Teknik Pengumpulan Data

Data dalam penelitian ini bersumber dari data primer dengan teknik pengumpulan data menggunakan kuesioner yang disebarkan kepada sampeI responden penelitian yang telah ditentukan. Kuesioner yang disebarkan berupa daftar pernyataan yang berkaitan dengan obyek yang diteliti.

3.4. Teknik Analisis Data

Analisis kuantitatif yang digunakan untuk mengelola data yang diperoleh dari kuesioner yang sudah diolah dalam bentuk angka dan dianalisis dengan perhitungan statistik, dengan mengunakan software IBM SPSS statistics 21. Adapun uji-uji yang dilakukan adalah analisis statistik deskriptif, uji kuaIitas data (uji validitas dan uji reliabilitas), uji 
asumsi kIasik (uji normalitas, uji multikolinearitas, uji heteroskedastisitas), uji regresi linear berganda dan uji hipotesis (uji signifikansi parsial/uji t, uji signifikansi simultan/uji $F$ dan uji koefisien determinasi/ $\mathrm{R}^{2}$ ).

\section{HASIL DAN PEMBAHASAN}

\subsection{Analisis Statistik Deskriptif}

Hasil analisis statistik deskriptif dapat dilihat pada tabel sebagai berikut :

Tabel 4.1. Analisis Statistik Deskriptif

Descriptive Statistics

\begin{tabular}{|l|c|c|c|c|c|}
\hline & $\mathrm{N}$ & Minimum & Maximum & Mean & Std. Deviation \\
\hline KPI & 66 & 33 & 50 & 44.58 & 3.981 \\
AI & 66 & 12 & 30 & 20.35 & 5.270 \\
KK & 66 & 17 & 35 & 26.53 & 3.771 \\
KAA & 66 & 32 & 50 & 42.58 & 4.591 \\
KKA & 66 & 28 & 70 & 59.41 & 11.086 \\
Valid N (listwise) & 66 & & & & \\
\hline
\end{tabular}

Sumber: Data primer diolah

Jika standar deviasinya Lebih besar dari mean maka nilai tersebut merupakan cerminan penyimpangan seluruh variabel independen dan variabel dependen. Data daIam variabel independen dan variabel dependen menunjukkan nilai mean yang Lebih besar dari standar deviasi maka hasil tersebut dapat dinyatakan baik.

\subsection{Uji Kualitas Data}

Berdasarkan uji validitas dan reliabilitas untuk seluruh variabel daIam penelitian ini, diperoleh hasil bahwa baik variabel independen maupun dependen memiliki hasil yang valid dan reliabeI sehingga instrumen dapat digunakan daIam penelitian.

\subsection{Uji Asumsi Klasik}

\subsubsection{Uji Normalitas}

Hasil uji normalitas dapat dilihat pada tabel berikut:

Tabel 4.2. Uji Normalitas

One-Sample Kolmogorov-Smirnov Test

\begin{tabular}{|ll|l|}
\hline & & Unstandardized Residual \\
\hline $\mathrm{N}$ & & 66 \\
Normal Parameters $\mathrm{a}, \mathrm{b}$ & Mean & .0000000 \\
& Std. Deviation & 9.31331803 \\
& Absolute & .121 \\
Most Extreme Differences & Positive & .070 \\
& Negative & -.121 \\
Kolmogorov-Smirnov Z & & .984 \\
Asymp. Sig. (2-tailed) & & .287 \\
\hline
\end{tabular}

a. Test distribution is Normal.

b. Calculated from data.

Sumber: Data primer diolah 
Dari tabel diatas, dapat diketahui bahwa data dalam penelitian ini berdistribusi normal karena nilai Asymp. Sig. (2tailed) adalah lebih dari 0,05 yaitu sebesar 0,287.

\subsubsection{Uji Multikolinieritias}

Hasil pengujian dapat dilihat pada tabel sebagai berikut :

\section{Tabel 4.3. Uji Multikolinearitas}

\begin{tabular}{|c|c|c|c|c|c|c|c|c|}
\hline \multicolumn{9}{|c|}{ Coefficients $^{\mathrm{a}}$} \\
\hline \multirow{2}{*}{\multicolumn{2}{|c|}{ Model }} & \multicolumn{2}{|c|}{$\begin{array}{l}\text { Unstandardized } \\
\text { Coefficients }\end{array}$} & \begin{tabular}{|l|} 
Standardized \\
Coefficients
\end{tabular} & \multirow[t]{2}{*}{$\mathrm{T}$} & \multirow[t]{2}{*}{ Sig. } & \multicolumn{2}{|c|}{$\begin{array}{l}\text { Collinearity } \\
\text { Statistics }\end{array}$} \\
\hline & & $B$ & Std. Error & Beta & & & Tolerance & VIF \\
\hline \multirow{5}{*}{1} & (Constant) & 39.299 & 16.209 & & 2.425 & .018 & & \\
\hline & KPI & -.690 & .318 & -.248 & -2.172 & .034 & .890 & 1.124 \\
\hline & AI & .848 & .237 & .403 & 3.576 & .001 & .911 & 1.098 \\
\hline & KK & .318 & .351 & .108 & .906 & .368 & .813 & 1.230 \\
\hline & KAA & .591 & .311 & .245 & 1.903 & .062 & .699 & 1.431 \\
\hline
\end{tabular}

a. Dependent Variable: KKA

Sumber: Data primer diolah

Dari tabel diatas, diketahui bahwa tidak ada multikolonieritas antar variabel dalam regresi pada penelitian ini karena nilai tolerance $>0,10$ dan nilai Variance Inflation Factor (VIF) juga menunjukkan semua variabel memiliki nilai $\mathrm{VIF}<10$.

\subsubsection{Uji Heteroskedastisitas}

Hasil uji heteroskedastisitas dengan uji glejser adalah sebagai berikut:

Tabel 4.4. Uji Heteroskedastisitas

\section{Coefficients ${ }^{\mathrm{a}}$}

\begin{tabular}{|c|c|c|c|c|c|c|}
\hline \multirow{2}{*}{\multicolumn{2}{|c|}{ Model }} & \multicolumn{2}{|c|}{$\begin{array}{l}\text { Unstandardized } \\
\text { Coefficients }\end{array}$} & $\begin{array}{l}\text { Standardized } \\
\text { Coefficients }\end{array}$ & \multirow[t]{2}{*}{$\mathrm{T}$} & \multirow[t]{2}{*}{ Sig. } \\
\hline & & B & Std. Error & Beta & & \\
\hline \multirow{5}{*}{1} & (Constant) & 17.193 & 9.224 & & 1.864 & .067 \\
\hline & KPI & .054 & . 181 & .038 & 297 & .767 \\
\hline & AI & -.261 & .135 & -.243 & - & .058 \\
\hline & KK & .156 & .200 & .104 & .779 & .439 \\
\hline & KAA & -.260 & . 177 & -.211 & $\begin{array}{l}- \\
1.470\end{array}$ & . 147 \\
\hline
\end{tabular}

a. Dependent Variable: Abs_Res

Sumber: Data primer diolah

Berdasarkan tabel di atas, diketahui bahwa nilai masingmasing variabel independen memiliki nilai signifikansi yang Lebih besar dari 0,05. Hal ini berarti tidak terdapat heteroskedastisitas pada data penelitian.

\subsection{Uji Regresi Linear Berganda}

Dari hasil perhitungan dengan bantuan software IBM SPSS statistics 21 diperoleh persamaan regresi sebagai berikut : 
Tabel 4.5. Uji Regresi Linear Berganda

Coefficients $^{a}$

\begin{tabular}{|ll|l|l|l|l|l|}
\hline \multirow{2}{*}{ Model } & \multicolumn{2}{|l|}{$\begin{array}{l}\text { Unstandardized } \\
\text { Coefficients }\end{array}$} & $\begin{array}{l}\text { Standardized } \\
\text { Coefficients }\end{array}$ & \multirow{2}{*}{ Sig. } \\
\cline { 2 - 4 } & B & Std. Error & Beta & & \\
\hline \multirow{2}{*}{\begin{tabular}{l} 
(Constant) \\
\multirow{2}{*}{1}
\end{tabular}} & 39.299 & 16.209 & & 2.425 & .018 \\
KPI & -.690 & .318 & -.248 & -2.172 & .034 \\
& AI & .848 & .237 & .403 & 3.576 & .001 \\
& KK & .318 & .351 & .108 & .906 & .368 \\
& KAA & .591 & .311 & .245 & 1.903 & .062 \\
\hline
\end{tabular}

a. Dependent Variable: KKA

Sumber: Data primer diolah

Model analisis regresi berganda di atas dapat dirumuskan sebagai berikut:

$\mathrm{KKA}=$ 39,299 - 0,690 KPI + 0,848 AI + 0,318 KK + 0,591 KAA + e

\subsubsection{Uji Signifikansi Parsial (Uji t)}

Hasil perhitungan uji $\mathrm{t}$ dengan menggunakan IBM SPSS statistics 21 adalah sebagai berikut:

Tabel 4.6. Uji Signifikansi Parsial (Uji t)

Coefficients ${ }^{\mathrm{a}}$

\begin{tabular}{|c|c|c|c|c|c|c|}
\hline \multirow{2}{*}{\multicolumn{2}{|c|}{ Model }} & \multicolumn{2}{|c|}{$\begin{array}{l}\text { Unstandardized } \\
\text { Coefficients }\end{array}$} & \multirow{2}{*}{$\begin{array}{l}\text { Standardized } \\
\text { Coefficients } \\
\text { Beta }\end{array}$} & \multirow[t]{2}{*}{$\mathrm{T}$} & \multirow[t]{2}{*}{ Sig. } \\
\hline & & B & Std. Error & & & \\
\hline \multirow{5}{*}{1} & (Constant) & 39.299 & 16.209 & & 2.425 & .018 \\
\hline & KPI & -.690 & .318 & -.248 & -2.172 & .034 \\
\hline & AI & .848 & .237 & .403 & 3.576 & .001 \\
\hline & KK & .318 & .351 & .108 & .906 & .368 \\
\hline & KAA & .591 & .311 & .245 & 1.903 & .062 \\
\hline
\end{tabular}

a. Dependent Variable: KKA

Sumber: Data primer diolah

Berdasarkan tabel di atas diketahui bahwa variabel independen keefektifan pengendalian internal dan asimetri informasi berpengaruh signifikan terhadap variabel dependen (kecenderungan kecurangan akuntansi) karena memiliki nilai signifikansi $<0,05$, sedangkan variabel independen kesesuaian kompensasi dan ketaatan aturan akuntansi tidak berpengaruh signifikan terhadap variabel dependen (kecenderungan kecurangan akuntansi) karena memiliki nilai signifikansi >0,05.

\subsubsection{Uji Signifikansi Simultan (Uji F)}

Hasil perhitungan uji $\mathrm{F}$ dengan menggunakan IBM SPSS statistics 21 adalah sebagai berikut: 
Tabel 4.7. Uji Signifikansi Simultan (Uji F)

ANOVA $^{\mathrm{a}}$

\begin{tabular}{|c|c|c|c|c|c|}
\hline Model & Sum of Squares & Df & Mean Square & $\mathrm{F}$ & Sig. \\
\hline $\begin{array}{ll} & \text { Regression } \\
1 & \text { Residual } \\
\text { Total }\end{array}$ & $\begin{array}{l}2349.992 \\
5637.963 \\
7987.955\end{array}$ & $\begin{array}{l}4 \\
61 \\
65\end{array}$ & $\begin{array}{l}587.498 \\
92.426\end{array}$ & 6.356 & $.000^{b}$ \\
\hline
\end{tabular}

a. Dependent Variable: KKA

b. Predictors: (Constant), KAA, AI, KPI, KK

Sumber: Data primer diolah

Berdasarkan tabel diatas dapat dilihat niliai signifikansi pada uji $\mathrm{F}$ sebesar 0.000 sehingga disimpulkan bahwa variabel independen secara simultan berpengaruh signifikan terhadap variabel dependen.

\subsubsection{Uji Koefisien Determinasi $\left(\mathbf{R}^{2}\right)$}

Hasil perhitungan koefisiensi determinasi $\left(R^{2}\right)$ dengan menggunakan IBM SPSS statistics 21 adalah sebagai berikut:

Tabel 4.8. Uji Koefisien Determinasi $\left(R^{2}\right)$

\section{Model Summary}

\begin{tabular}{|l|l|l|l|l|}
\hline Model & R & R Square & Adjusted R Square & Std. Error of the Estimate \\
\hline 1 & $.542^{\mathrm{a}}$ & .294 & .248 & 9.614 \\
\hline
\end{tabular}

a. Predictors: (Constant), KAA, AI, KPI, KK

Sumber: Data primer diolah

Dari tabel model summary di atas dapat diketahui nilai Adjusted $R$ Square sebesar 0,248. Hal ini berarti variabel dependen (kecenderungan kecurangan akuntansi) mampu dijelaskan atau diprediksi oleh variabel keefektifan pengendalian internal, asimetri informasi, kesesuaian kompensasi dan ketaatan aturan akuntansi sebesar 24,8\%, sedangka 75,2\% lainnya dipengaruhi oleh variabel lainnya di luar penelitian ini seperti moralitas individu, penegakan hukum, kultur organisasi, motivasi, budaya etis organisasi, perilaku tidak etis, implementasi good governance dan keadilan organsiasi.

\section{PEMBAHASAN}

\subsection{Pengaruh Keefektifan Pengendalian Internal terhadap Kecenderungan Kecurangan Akuntansi pada OPD Kabupaten Kendal}

Berdasarkan hasil uji hipotesis, variabel keefektifan pengendalian internal memiliki nilai signifikansi sebesar 0,034 sehingga hal ini membuktikan bahwa variabel tersebut berpengaruh signifikan 
terhadap kecenderungan kecurangan akuntansi pada OPD Kabupaten Kendal. Hal tersebut berarti apabila sistem pengendalian dilakukan secara efektif, maka kegiatan operasional instansi juga dapat dilaksanakan secara efektif dan efisien sehingga kemungkinan adanya kecurangan dalam aktivitas operasional instansi juga dapat diminimalisir.

Hasil penelitian ini sejalan dengan penelitian yang dilakukan oleh Yunita Handayani (2018) yang menunjukkan bahwa keefektifan pengendalian internal berpengaruh signifikan terhadap kecenderungan kecurangan akuntansi.

5.2. Pengaruh Asimetri Informasi terhadap Kecenderungan Kecurangan Akuntansi pada OPD Kabupaten Kendal

Berdasarkan hasil uji hipotesis, variabel asimetri informasi memiliki nilai signifikansi sebesar 0,001 sehingga hal ini membuktikan bahwa variabel tersebut berpengaruh signifikan terhadap kecenderungan kecurangan akuntansi pada OPD Kabupaten Kendal. Hal tersebut berarti apabila tingkat asimetri informasi pada suatu instansi tergolong tinggi, maka kecenderungan kecurangan akuntansi yang dilakukan oleh pegawai juga semakin meningkat.

Hasil penelitian ini sejalan dengan penelitian yang dilakukan oleh Adi Putra Pratama Nugraha (2018) menunjukkan bahwa asimetri informasi berpengaruh signifikan terhadap kecenderungan kecurangan akuntansi.

5.3. Pengaruh Kesesuaian Kompensasi terhadap Kecenderungan Kecurangan Akuntansi pada OPD Kabupaten Kendal

Berdasarkan hasil uji hipotesis, variabel kesesuaian kompensasi memiliki nilai signifikansi sebesar 0,368 . Hal ini membuktikan bahwa variabel tersebut tidak berpengaruh signifikan terhadap kecenderungan kecurangan akuntansi pada OPD Kabupaten Kendal. Berdasarkan pengujian regresi tersebut, dapat dinyatakan bahwa meskipun tingkat kesesuaian kompensasi tinggi, akan tetapi tidak mengurangi kecenderungan kecurangan akuntansi pada OPD Kabupaten Kendal.

Hasil penelitian ini sejalan dengan penelitian yang dilakukan oleh Yunita Handayani (2018) yang menunjukkan hasil bahwa kesesuaian kompensasi tidak berpengaruh terhadap kecenderungan kecurangan akuntansi.

5.4. Pengaruh Ketaatan Aturan Akuntansi terhadap Kecenderungan Kecurangan Akuntansi pada OPD Kabupaten Kendal

Berdasarkan hasil uji hipotesis, variabel ketaatan aturan akuntansi memiliki nilai signifikansi sebesar 0,062. Hal ini membuktikan bahwa variabel tersebut tidak berpengaruh signifikan terhadap kecenderungan kecurangan akuntansi. Sehingga berdasarkan pengujian regresi, dapat dinyatakan bahwa meskipun tingkat ketaatan 
aturan akuntansi tinggi, akan tetapi tidak mengurangi kecenderungan kecurangan akuntansi pada OPD Kabupaten Kendal.

Hasil penelitian ini sejalan dengan penelitian yang dilakukan oleh Rifandra Adwitya dan Vita Fitria Sari (2017) yang juga menunjukkan hasil bahwa ketaatan aturan akuntansi tidak berpengaruh signifikan terhadap kecenderungan kecurangan akuntansi.

5.5. Pengaruh Keefektifan Pengendalian Internal, Asimetri Informasi, Kesesuaian Kompensasi dan Ketaatan Aturan Akuntansi terhadap Kecenderungan Kecurangan Akuntansi pada OPD Kabupaten Kendal

Berdasarkan uji F, nilai signifikansi untuk seluruh variabel independen terhadap variabel dependen adalah sebesar 0,000. Hal tersebut berarti seluruh variabel independen dalam penelitian ini secara simultan berpengaruh signifikan terhadap kecenderungan kecurangan akuntansi pada OPD Kabupaten Kendal.

\section{KESIMPULAN DAN SARAN}

\subsection{Kesimpulan}

Berdasarkan hasil yang diperoleh dalam penelitian ini, maka dapat disimpulkan sebagai berikut :

6.1.1. Secara parsial, variabel independen keefektifan pengendalian internal dan asimetri informasi memiliki pengaruh signifikan terhadap variabel dependen kecenderungan kecurangan akuntansi pada OPD Kabupaten Kendal, sedangkan variabel kesesuaian kompensasi dan ketaatan aturan akuntansi tidak memiliki pengaruh signifikan terhadap variabel dependen kecenderungan kecurangan akuntansi.

6.1.2. Secara simultan, variabel independen keefektifan pengendalian internal, asimetri informasi, kesesuaian kompensasi dan ketaatan aturan akuntansi memiliki pengaruh signifikan terhadap variabel dependen kecenderungan kecurangan akuntansi pada OPD Kabupaten Kendal.

6.1.3. Nilai koefisien determinasi $\left(R^{2}\right)$ menunjukkan hasil sebesar 0,248, hal ini dapat dijelaskan bahwa $24,8 \%$ variabel dependen kecenderungan kecurangan akuntansi dapat dipengaruhi oleh variabel independen keefektifan pengendaIian internal, asimetri informasi, kesesuaian kompensasi dan ketaatan aturan akuntansi.

\subsection{Saran}

Saran untuk penelitian selanjutnya adalah sebagai berikut:

6.2.1. Penambahan variabel independen yang berkaitan dengan kecenderungan kecurangan akuntansi diharapkan dilakukan oleh peneliti selanjutnya sehingga dalam penelitian selanjutnya memperoleh hasil yang lebih luas mengenai faktor lainnya yang dapat mempengaruhi kecenderungan kecurangan akuntansi 
seperti moralitas individu, penegakan hukum, kultur organisasi, motivasi, budaya etis organisasi, perilaku tidak etis, implementasi good governance dan keadilan organsiasi.

6.2.2. Penelitian ini hanya mengambil sampel pada dinas dan badan Kabupaten Kendal, sehingga penambahan jumlah sampel yang digunakan seperti kecamatan pada Kabupaten Kendal diharapkan dilakukan oleh peneliti selanjutnya.

\section{REFERENSI}

Ajzen, I. (1991). Theory of Planned Behavior. Organizational Behaviour and Human Decision Processes. 50(2), 179-211.

Cnnindonesia.com. (2020). Survei TII: DPR Lembaga Paling Korup diambil dari https:// www.cnnindonesia.com/nasional/20201204075231-32-

577831/ survei-tii-dpr-lembaga-paling-korup.

Firdaus, M. H. Z. (2018). Analisis Faktor-faktor Yang Mempengaruhi Kecenderungan Pegawai Melakukan Kecurangan/Fraud Pada Sektor Pemerintahan (Studi Kasus Pada Pemerintahan di Kabupaten Klaten). Skripsi. Universitas Islam Indonesia.

Ghozali, I. (2018). Aplikasi Analissis Multivariate Dengan Program IBM SPSS 25. Semarang: Universitas Diponegoro.

Handayani, Y. (2018). Pengaruh Keefektifan Pengendalian Internal, Moralitas Individu dan Kesesuaian Kompensasi Terhadap Kecenderungan Kecurangan Akuntansi (Studi Kasus Pada Pemerintah Daerah Kota Tegal). Skripsi. STIE Muhammadiyah Pekalongan.

Hasibuan, M. S. (2017). Manajemen Sumber Daya Manusia. PT Bumi Aksara.

Mardiasmo. (2017). Perpajakan Edisi Terbaru. Yogyakarta: Andi.

Nugraha, A. (2018). Pengaruh Keefektifan Pengendalian Internal, Kultur Organisasi dan Asimetri Informasi Terhadap Tindakan Accounting Fraud. 138.

Shintadevi, P. F. (2015). Pengaruh Keefektifan Pengendalian Internal, Ketaatan Aturan Akuntansi dan Kesesuaian Kompensasi Terhadap Kecenderungan Kecurangan Akuntansi dengan Perilaku Tidak Etis Sebagai Variabel Intervening Pada Universitas Negeri Yogyakarta. Skripsi. Universitas Negeri Yogyakarta.

Sugiyono. (2012). Statistika untuk Penelitian. CV Alfabeta.

Thoyibatun, S. (2009). Faktor-faktor yang Berpengaruh terhadap Perilaku Tidak Etis dan Kecenderungan Kecurangan Akuntansi Serta Akibatnya terhadap Kinerja Organisasi. Jurnal Ekonomi Dan Keuangan.

Umar, H. (2011). Metode Penelitian Untuk Skripsi dan Tesis Bisnis. PT Raja Grafindo Persada.

Wilopo. (2006). Analisis Faktor-faktor Yang Berpengaruh Terhadap Kecenderungan Kecurangan Akuntansi: Studi Pada Perusahaan Publik dan Badan Usaha Milik Negara di Indonesia. Simposium Nasional Akuntansi 9. 